\title{
Adolescent Weight Status and Self-Reported School Performance in South Korea
}

\author{
Young Kyung Do and Eric Andrew Finkelstein
}

Program in Health Services and Systems Research, Duke-NUS Graduate Medical School Singapore, Singapore 169857

Correspondence should be addressed to Young Kyung Do, young.do@duke-nus.edu.sg

Received 6 July 2011; Revised 1 September 2011; Accepted 1 September 2011

Academic Editor: Jack A. Yanovski

Copyright ( $) 2011$ Y. K. Do and E. A. Finkelstein. This is an open access article distributed under the Creative Commons Attribution License, which permits unrestricted use, distribution, and reproduction in any medium, provided the original work is properly cited.

Using a nationally representative sample of 142783 middle school (13-15 years old) and high school (16-18 years old) students in South Korea, this study examined whether (1) overweight and obesity are more likely to be associated with lower self-reported school performance; (2) overweight and obese students are more likely to enrol in a vocational high school as opposed to a general high school; (3) the association between obesity and poorer self-reported school performance is mediated through body image stress and health status. We found that excess weight was negatively associated with self-reported school performance among middle and general high school students, and that obese students had a higher probability of being enrolled in a vocational over a general high school. We did not find strong evidence on the mediating role of body image stress and health status.

\section{Introduction}

Obesity is a growing public health problem worldwide [1]. In addition to the well-known negative health consequences, recent studies have found that obesity is associated with poorer labor market outcomes among adults, including longer spells of unemployment and lower wages [2-6]. It is possible that these labor market effects are a direct result of adverse health consequences that lower the marginal product of labor among obese workers [5]. However, because poorer labor market outcomes are evident in younger obese populations [7], where the adverse health effects of obesity are small, it is likely that other factors are at least partly responsible.

One hypothesis is that the negative labor market impacts of obesity are owed to a lower stock of education, which also reduces the marginal product of labor and thus suppresses wages among obese individuals [7]. Consistent with this hypothesis, Fowler-Brown et al. report that adolescent obesity is associated with a lower likelihood of college completion [8]. Given this finding, one natural question is how early in life and through what mechanism excess weight leads to poorer educational outcomes.
For adolescents, a negative association between excess weight and school performance has been shown in several studies in the USA and Europe [9-11] as well as in Asian countries $[12,13]$. Results for younger ages are less consistent. For example, Mo-suwan et al. [13] found that overweight and becoming overweight was associated with poorer school performance among young adolescents (7th9th graders), but not among children (3rd-6th graders). Other studies, however, found that excess weight was associated with adverse school outcomes even during the first six years in school [14-16].

Several studies note that the association between excess weight and lower school performance was explained largely by individual or family characteristics, or by other contextual factors of the school environment $[14,16]$. For example, Crosnoe and Muller [17] find that the negative association between excess weight and academic achievement is more pronounced in school contexts where stigmatization of obesity is more likely, such as in schools with higher rates of romantic activity (based on adolescent reports of current romantic involvement with a specific person) and a lower average body size. Krukowski et al. [18] find that weightbased teasing mediates the association between overweight 
and poorer academic performance. The paper suggests that the psychological stress associated with obesity may be an important mediator of lower school performance.

In this study, we revisit the relationship between excess weight and self-reported school performance among adolescents using a large, nationally representative sample of South Korean adolescents (7th-12th grade). Extending this body of literature to South Korea is interesting in light of the growing obesity epidemic in Asia and because South Korean culture places significant emphasis on conforming to social norms. As a result, the psychological stress associated with excess weight may be more pronounced [19], and the adverse effects of obesity on self-reported school performance may be greater than in the USA or in other western countries where childhood obesity rates are much higher and perhaps less stigmatized. The negative health effects of obesity may be small among adolescents as a group; nonetheless, it is possible that these adverse health effects may be considerable among older obese adolescents. Hence, we examine whether health status serves as a mediator of poorer school performance among obese adolescents, with reference to potential differences between younger and older adolescents.

Given this motivation, we test three hypotheses: (1) overweight and obesity are more likely to be associated with lower self-reported school performance; (2) overweight and obese children are more likely to enrol in a vocational high school as opposed to a general high school; (3) the association between obesity and poorer school performance is mediated through body image stress and poorer health. In particular, we examine how the relationships described in the hypotheses may vary by gender and school type.

\section{Subjects and Methods}

2.1. Data. This study used a sample of 142783 adolescents from the 2006 and 2007 Korean Youth Health Risk Behavior Online Survey-an annually repeated, cross-sectional survey designed to monitor adolescent health behavior and risk factors. The survey used a multistage, cluster-sample design to obtain a nationally representative sample of middle school (ages of 13-15 years) and high school students (ages of 16-18 years) in South Korea. Response rates were 91\% (71 404 out of the target sample of 78593 ) in 2006 and 95\% (74698 out of the target sample of 78834 ) in 2007 [20]. After receiving directions from a trained support teacher, respondents anonymously completed the survey in a school computer room.

2.2. Variables. Our first dependent variable was a fivecategory ordinal variable of self-reported school performance (Low, Mid-low, Middle, Mid-high, and High) derived from the survey question, "What is your school performance during the past 12 months?" Although this variable is subjective in nature, Korean adolescents receive feedback on their school performance (based on grading on the curve) through frequent standardized tests and can report accurately on their school performance. Our second dependent variable of interest was a binary outcome for enrolment in a vocational high school (versus general high school). In the Korean secondary education system, middle school students advance to either a general or vocational high school (roughly 25\% in 2005). Compared with students in general high schools, students in vocational high schools are more likely to drop out from school and less likely to enter college upon graduation [21].

The primary independent variables indicating weight status were based on gender- and age-specific cut-off points for body mass index (BMI) according to the Korea Centers for Disease Control and Prevention criteria (obesity: $\geq 95$ th percentile, overweight: $\geq 85$ th percentile but $<95$ th percentile, normal weight: $\geq 5$ th percentile but $<85$ th percentile, and underweight: $<5$ th percentile) [22, 23]. For example, BMI cut-off points among male adolescents aged 15 were 27.77 (95th percentile), 24.74 (95th percentile), and 16.83 (5th percentile), respectively; the corresponding cut-off points for female adolescents aged 15 were 26.11, 23.67, and 16.78 .

Two potential mediators were considered: self-reported body image stress (a binary indicator variable) and selfreported health status (Excellent, Good, Fair, Poor, or Very poor) [24-26]. The binary variable of body image stress was defined as " 1 " (versus " 0 " otherwise) if the respondent chose physical appearance to the question, "What is the major cause of stress for your life?" Other explanatory variables included a number of factors that may influence adolescent school performance: both father's and mother's education levels (College or more, High school, Middle school, or Don't know); household economic status (High, Middle, or Low) and number of cars $(0,1$, or $2+)$; whether the respondent has his/her own bedroom; number of computers at home $(0,1$, 2, or 3+); residential area type (Metropolitan, Rural, or Midsized town); school level within each school type (1st, $2 n d$, or $3 r d)$; survey year (2007 versus 2006).

2.3. Statistical Analysis. Ordered probit models were estimated to examine the associations between self-reported school performance and weight status, controlling for the full set of other explanatory variables. Separate analyses were conducted by gender (male and female) and school type (middle school, general high, and vocational high). Using parameter estimates from these six ordered probit models, we obtained mean predicted probabilities for each of the five categories of self-reported school performance by weight status. To examine the potential mediating role of body image stress and health status, we re-estimated similar ordered probit models three more times, each using a different restricted set of explanatory variables from the full model, namely, without body image stress, without health status, and without body image stress and health status. Finally, we estimated a probit model of the probability of a first-year high school student being enrolled in a vocational (versus general) high school. This probit model was estimated among first-year high school students only to abstract from the issue of reverse causality, where school type could affect weight status. Sampling weights and clustering were taken into account. Stata 12.0 was used for all analyses (StataCorp, College Station, TX). 
TABLE 1: Summary statistics of the study sample $(N=142783)$.

\begin{tabular}{|c|c|c|c|c|}
\hline Variables & $\begin{array}{c}\text { Underweight } \\
(n=9649)\end{array}$ & $\begin{array}{l}\text { Normal weight } \\
(n=114291)\end{array}$ & $\begin{array}{l}\text { Overweight } \\
(n=12788)\end{array}$ & $\begin{array}{c}\text { Obesity } \\
(n=6055)\end{array}$ \\
\hline \multicolumn{5}{|c|}{ Self-reported school performance } \\
\hline High & 13.4 & 13.3 & 11.3 & 9.5 \\
\hline Mid-high & 23.3 & 26.0 & 24.7 & 21.2 \\
\hline Middle & 26.1 & 26.9 & 25.3 & 24.7 \\
\hline Mid-low & 24.3 & 23.3 & 26.1 & 27.5 \\
\hline Low & 12.9 & 10.4 & 12.6 & 17.1 \\
\hline Body image stress & 9.1 & 9.9 & 14.1 & 17.7 \\
\hline \multicolumn{5}{|l|}{ Health status } \\
\hline Excellent & 10.8 & 17.3 & 17.7 & 13.9 \\
\hline Good & 35.9 & 46.6 & 45.4 & 42.1 \\
\hline Fair & 36.0 & 28.1 & 28.3 & 31.6 \\
\hline Poor & 15.8 & 7.6 & 8.1 & 11.2 \\
\hline Very poor & 1.6 & 0.5 & 0.5 & 1.2 \\
\hline \multicolumn{5}{|l|}{ Father's education } \\
\hline College or more & 39.7 & 42.9 & 40.3 & 34.9 \\
\hline High school & 39.1 & 38.4 & 39.9 & 42.3 \\
\hline Middle school & 7.1 & 6.9 & 7.5 & 9.6 \\
\hline Don’t know & 14.1 & 11.8 & 12.3 & 13.2 \\
\hline \multicolumn{5}{|l|}{ Mother's education } \\
\hline College or more & 27.1 & 29.2 & 27.0 & 24.0 \\
\hline High school & 49.6 & 50.3 & 51.3 & 50.4 \\
\hline Middle school & 8.7 & 8.1 & 8.9 & 11.7 \\
\hline Don’t know & 14.6 & 12.4 & 12.9 & 13.9 \\
\hline \multicolumn{5}{|l|}{ Household economic status } \\
\hline High & 6.4 & 6.9 & 7.3 & 6.0 \\
\hline Middle & 87.8 & 88.1 & 86.6 & 85.7 \\
\hline Low & 5.9 & 5.0 & 6.1 & 8.3 \\
\hline \multicolumn{5}{|l|}{ Number of cars at home } \\
\hline 0 & 19.3 & 16.8 & 17.9 & 19.7 \\
\hline 1 & 58.7 & 58.0 & 56.7 & 56.0 \\
\hline 2 or more & 22.0 & 25.1 & 25.4 & 24.4 \\
\hline No bedroom for the student & 25.5 & 23.2 & 23.7 & 24.2 \\
\hline \multicolumn{5}{|l|}{ Number of computers at home } \\
\hline 0 & 4.4 & 3.6 & 3.6 & 4.2 \\
\hline 1 & 62.4 & 62.5 & 61.9 & 62.7 \\
\hline 2 & 26.4 & 26.8 & 27.6 & 26.4 \\
\hline 3 or more & 6.9 & 7.1 & 7.0 & 6.7 \\
\hline \multicolumn{5}{|l|}{ Residence area } \\
\hline Metropolitan & 50.2 & 51.5 & 53.3 & 53.8 \\
\hline Rural & 7.6 & 7.2 & 7.2 & 7.7 \\
\hline Mid-sized town & 42.2 & 41.3 & 39.6 & 38.5 \\
\hline
\end{tabular}

Notes: All numbers are in percent. Sampling weights are applied.

\section{Results}

Table 1 presents summary statistics for the study sample by weight status. Overall, obesity is associated with lower self-reported school performance: $17.1 \%$ of obese students report the lowest category of school performance (Low) compared with only $10.4 \%$ among those with normal weight.
Compared with other categories of weight status, a higher percentage of obese students report body image stress and very poor health status. In terms of other socioeconomic indicators, obesity is associated with lower economic status.

Predicted probabilities by weight status for each of the five categories of self-reported school performance from the ordered probit models are shown in Table 2. All else being 
TABLE 2: Predicted probabilities for self-reported school performance categories by weight status.

\begin{tabular}{|c|c|c|c|c|c|}
\hline \multirow{2}{*}{$\begin{array}{l}\text { Sample by gender and } \\
\text { school type }\end{array}$} & & \multicolumn{4}{|c|}{$\begin{array}{l}\text { Mean of predicted probabilities (\%) for each category of self-reported school performance by } \\
\text { weight status ( } 95 \% \text { Confidence Interval) }\end{array}$} \\
\hline & & Underweight & Normal weight & Overweight & Obesity \\
\hline \multicolumn{6}{|l|}{ Middle school } \\
\hline \multirow[t]{5}{*}{$(N=39213)$} & High & $13.9(13.0,14.8)$ & $15.1(14.7,15.5)$ & $13.1(12.4,13.9)$ & $11.4(10.4,12.3)$ \\
\hline & Mid-high & $24.4(23.7,25.1)$ & $25.2(24.8,25.6)$ & $23.8(23.2,24.5)$ & $22.4(21.4,23.3)$ \\
\hline & Middle & $26.5(26.1,27.0)$ & $26.4(26.0,26.9)$ & $26.6(26.1,27.0)$ & $26.5(26.1,26.9)$ \\
\hline & Mid-low & $23.1(22.3,23.9)$ & $22.2(21.8,22.6)$ & $23.7(23.0,24.4)$ & $25.1(24.2,26.0)$ \\
\hline & Low & $12.1(11.3,12.9)$ & $11.1(10.8,11.4)$ & $12.8(12.1,13.5)$ & $14.7(13.6,15.8)$ \\
\hline \multicolumn{6}{|l|}{ General high school } \\
\hline \multirow[t]{5}{*}{$(N=24988)$} & High & $10.7(9.7,11.8)$ & $12.1(11.7,12.5)$ & $11.8(11.0,12.7)$ & $8.8(7.8,9.8)$ \\
\hline & Mid-high & $24.4(23.3,25.6)$ & $25.7(25.2,26.3)$ & $25.5(24.6,26.4)$ & $22.3(21.1,23.5)$ \\
\hline & Middle & $27.8(27.3,28.4)$ & $27.8(27.3,28.4)$ & $27.8(27.3,28.4)$ & $27.6(27.0,28.2)$ \\
\hline & Mid-low & $25.0(23.8,26.1)$ & $23.7(23.2,24.2)$ & $23.9(23.0,24.8)$ & $26.8(25.8,27.9)$ \\
\hline & Low & $12.0(10.9,13.2)$ & $10.7(10.3,11.1)$ & $10.9(10.1,11.7)$ & $14.4(13.0,15.8)$ \\
\hline \multicolumn{6}{|l|}{$\begin{array}{l}\text { Vocational high } \\
\text { school }\end{array}$} \\
\hline \multirow[t]{5}{*}{$(N=10600)$} & High & $12.3(10.8,13.7)$ & $12.0(11.3,12.7)$ & $11.9(10.5,13.2)$ & $10.5(9.0,12.0)$ \\
\hline & Mid-high & $23.6(22.2,25.0)$ & $23.4(22.6,24.3)$ & $23.3(22.0,24.6)$ & $22.1(20.4,23.7)$ \\
\hline & Middle & $25.5(24.7,26.3)$ & $25.5(24.6,26.3)$ & $25.5(24.6,26.3)$ & $25.3(24.4,26.2)$ \\
\hline & Mid-low & $25.1(23.7,26.4)$ & $25.3(24.4,26.1)$ & $25.4(24.2,26.7)$ & $26.5(25.0,28.0)$ \\
\hline & Low & $13.5(12.0,15.1)$ & $13.8(13.1,14.5)$ & $14.0(12.6,15.4)$ & $15.6(13.6,17.6)$ \\
\hline Panel B: Female & & Underweight & Normal weight & Overweight & Obesity \\
\hline \multicolumn{6}{|l|}{ Middle school } \\
\hline \multirow[t]{5}{*}{$(N=35214)$} & High & $13.9(13.0,14.9)$ & $14.5(14.1,14.8)$ & $11.7(10.9,12.4)$ & $8.8(7.9,9.8)$ \\
\hline & Mid-high & $25.9(25.1,26.8)$ & $26.3(25.8,26.8)$ & $24.1(23.4,24.8)$ & $21.2(20.1,22.3)$ \\
\hline & Middle & $26.2(25.8,26.7)$ & $26.2(25.7,26.6)$ & $26.3(25.9,26.8)$ & $26.0(25.4,26.5)$ \\
\hline & Mid-low & $23.4(22.5,24.3)$ & $23.0(22.5,23.4)$ & $25.3(24.6,26.1)$ & $27.9(27.0,28.9)$ \\
\hline & Low & $10.5(9.7,11.3)$ & $10.1(9.8,10.4)$ & $12.5(11.8,13.3)$ & $16.0(14.7,17.4)$ \\
\hline \multicolumn{6}{|l|}{ General high school } \\
\hline \multirow[t]{5}{*}{$(N=22752)$} & High & $10.0(9.1,10.8)$ & $10.1(9.7,10.5)$ & $8.7(7.9,9.6)$ & $7.3(6.2,8.4)$ \\
\hline & Mid-high & $26.4(25.3,27.5)$ & $26.6(26.0,27.2)$ & $24.9(23.8,26.0)$ & $22.9(21.3,24.6)$ \\
\hline & Middle & $29.4(28.8,30.0)$ & $29.4(28.8,30.0)$ & $29.4(28.8,30.0)$ & $29.1(28.5,29.8)$ \\
\hline & Mid-low & $25.0(24.0,26.1)$ & $24.8(24.3,25.4)$ & $26.5(25.4,27.6)$ & $28.3(26.8,29.9)$ \\
\hline & Low & $12.2(10.6,10.6)$ & $9.0(8.6,9.4)$ & $10.5(9.5,11.4)$ & $12.3(10.7,13.9)$ \\
\hline \multicolumn{6}{|l|}{$\begin{array}{l}\text { Vocational high } \\
\text { school }\end{array}$} \\
\hline \multirow[t]{5}{*}{$(N=10016)$} & High & $10.0(8.7,11.4)$ & $10.4(9.8,11.0)$ & $10.0(8.7,11.4)$ & $9.4(7.9,10.9)$ \\
\hline & Mid-high & $23.7(22.2,25.2)$ & $24.1(23.2,24.9)$ & $23.7(22.2,25.2)$ & $23.0(21.2,24.8)$ \\
\hline & Middle & $27.3(26.4,28.2)$ & $27.3(26.4,28.2)$ & $27.3(26.4,28.2)$ & $27.2(26.3,28.1)$ \\
\hline & Mid-low & $26.8(25.3,28.4)$ & $26.5(25.6,27.4)$ & $26.8(25.3,28.3)$ & $27.5(25.7,29.2)$ \\
\hline & Low & $12.2(10.6,13.7)$ & $11.8(11.1,12.4)$ & $12.2(10.7,13.6)$ & $12.9(11.0,14.8)$ \\
\hline
\end{tabular}

Notes: Predicted probabilities (in \%) were obtained from ordered probit models controlling for body image stress, self-reported health status, father's and mother's education, household economic status, number of cars at home, having no bedroom for the student, number of computers at home, residence area type, school level, and survey year. Confidence Intervals are based on bootstrapped standard errors obtained from 1000 replications.

equal, male, middle school students with obesity are more likely to be in the Low category compared with their normal weight counterparts (14.7\% versus $11.1 \%)$. Likewise, female, middle school students with obesity are more likely to report Low than those with normal weight (16.0\% versus $10.1 \%)$.
For vocational high school students (both male and female), predicted probabilities for self-reported school performance do not differ much by weight status.

Table 3 shows that coefficient estimates on weight status in the three restricted models (Panels A, B, and C) change 
TABLE 3: Ordered probit regression analysis of self-reported school performance ${ }^{\dagger}$.

\begin{tabular}{|c|c|c|c|c|c|c|}
\hline \multirow{2}{*}{ Variables } & \multicolumn{3}{|c|}{ Male } & \multicolumn{3}{|c|}{ Female } \\
\hline & Middle school & General high & $\begin{array}{c}\text { Vocational } \\
\text { high }\end{array}$ & Middle school & General high & $\begin{array}{c}\text { Vocational } \\
\text { high }\end{array}$ \\
\hline \multicolumn{7}{|c|}{ Panel A: Neither body image stress included } \\
\hline \multicolumn{7}{|c|}{ Weight status (ref.: Normal weight) } \\
\hline Obesity & $-0.21^{* *}$ & $-0.21^{* *}$ & $-0.09^{*}$ & $-0.33^{* *}$ & $-0.20^{* *}$ & -0.07 \\
\hline Overweight & $-0.10^{* *}$ & -0.02 & -0.02 & $-0.15^{* *}$ & $-0.10^{* *}$ & -0.02 \\
\hline Underweight & $-0.07^{* *}$ & $-0.09^{* *}$ & -0.01 & -0.02 & -0.01 & -0.03 \\
\hline \multicolumn{7}{|c|}{ Panel B: Body image stress included } \\
\hline \multicolumn{7}{|c|}{ Weight status (ref.: Normal weight) } \\
\hline Obesity & $-0.21^{* *}$ & $-0.20^{* *}$ & $-0.09^{*}$ & $-0.31^{* *}$ & $-0.18^{* *}$ & -0.06 \\
\hline Overweight & $-0.10^{* *}$ & -0.02 & -0.01 & $-0.14^{* *}$ & $-0.09^{* *}$ & -0.02 \\
\hline Underweight & $-0.07 * *$ & $-0.09^{* *}$ & -0.01 & -0.03 & -0.01 & -0.03 \\
\hline Body image stress & 0.01 & $-0.09^{* *}$ & $-0.06^{*}$ & $-0.10^{* *}$ & $-0.21^{* *}$ & $-0.08^{* *}$ \\
\hline \multicolumn{7}{|c|}{ Panel C: Health status included } \\
\hline \multicolumn{7}{|c|}{ Weight status (ref.: Normal weight) } \\
\hline Obesity & $-0.19^{* *}$ & $-0.20^{* *}$ & -0.08 & $-0.33^{* *}$ & $-0.20^{* *}$ & -0.07 \\
\hline Overweight & $-0.10^{* *}$ & -0.02 & -0.01 & $-0.15^{* *}$ & $-0.10^{* *}$ & -0.03 \\
\hline Underweight & $-0.06^{*}$ & $-0.08^{*}$ & 0.01 & -0.01 & -0.01 & -0.02 \\
\hline \multicolumn{7}{|c|}{ Health status (ref.: Excellent) } \\
\hline Good & $0.04^{* *}$ & 0.01 & -0.02 & $0.04^{*}$ & $0.09^{* *}$ & 0.03 \\
\hline Fair & $-0.05^{* *}$ & $-0.04^{*}$ & $-0.11^{* *}$ & -0.01 & 0.04 & 0.01 \\
\hline Poor & $-0.06^{*}$ & -0.04 & $-0.18^{* *}$ & -0.01 & 0.06 & -0.04 \\
\hline Very poor & -0.13 & $-0.23^{*}$ & $-0.37^{*}$ & $-0.52^{* *}$ & $-0.26^{*}$ & -0.18 \\
\hline \multicolumn{7}{|c|}{ Panel D: Both body image stress and health status included } \\
\hline \multicolumn{7}{|c|}{ Weight status (ref.: Normal weight) } \\
\hline Obesity & $-0.20^{* *}$ & $-0.19^{* *}$ & -0.08 & $-0.31^{* *}$ & $-0.18^{* *}$ & -0.06 \\
\hline Overweight & $-0.10^{* *}$ & -0.02 & -0.01 & $-0.14^{* *}$ & $-0.09^{* *}$ & -0.02 \\
\hline Underweight & $-0.06^{*}$ & $-0.08^{*}$ & 0.01 & -0.02 & -0.01 & -0.02 \\
\hline Body image stress & 0.02 & $-0.09^{* *}$ & $-0.06^{*}$ & $-0.10^{* *}$ & $-0.21^{* *}$ & $-0.08^{* *}$ \\
\hline \multicolumn{7}{|c|}{ Health status (ref.: Excellent) } \\
\hline Good & $0.04^{* *}$ & 0.01 & -0.02 & $0.04^{*}$ & $0.09^{* *}$ & 0.03 \\
\hline Fair & $-0.05^{* *}$ & $-0.04^{*}$ & $-0.11^{* *}$ & -0.02 & 0.04 & 0.01 \\
\hline Poor & $-0.06^{*}$ & -0.04 & $-0.17^{* *}$ & -0.01 & 0.05 & -0.05 \\
\hline Very poor & -0.14 & $-0.23^{*}$ & $-0.37^{*}$ & $-0.52^{* *}$ & $-0.27^{*}$ & -0.18 \\
\hline
\end{tabular}

Notes: ${ }^{\dagger}$ Values for the dependent variable increase with better self-reported school performance: from Low, Mid-low, Middle, Mid-high to High. Coefficients are shown. ${ }^{* *} P<0.01,{ }^{*} P<0.05$. Panel D full model results are estimates from Table 2. Covariates include father's and mother's education, household economic status, number of cars at home, having no bedroom for the student, number of computers at home, residence area type, school level, and survey year.

little, if at all, in magnitude or statistical significance from corresponding coefficient estimates of the full model (Panel D). Overall, both body image stress and poorer health status are statistically significantly associated with lower academic performance. However, the small differences on coefficient estimates of weight status between the full and restricted models suggest that body image stress and health status may not play an important role in mediating this association.

Finally, obesity is associated with a higher likelihood of being enrolled in a vocational over a general high school among both male and female first-year high school students (Table 4). Even after including potential mediators, the magnitude of the marginal probabilities does not vary considerably. The likelihood of being enrolled in a vocational school for male obese students is 8.6 percentage points higher than their normal weight counterparts. This effect is even greater for female obese students whose marginal probability of being in a vocational high school is 10.6 percentage points higher than those with normal weight.

\section{Discussion}

Overall, our findings indicate that among South Korean adolescents, overweight and obesity are more likely to be associated with lower self-reported school performance, and that obese adolescents are more likely to be enrolled in a 
TABLE 4: Marginal probabilities (in percentage points) of being enrolled in vocational high school (versus general high school) among first-year high school students.

\begin{tabular}{|c|c|c|}
\hline Variables & Male & Female \\
\hline \multicolumn{3}{|c|}{ Panel A: Neither body image stress nor health status included } \\
\hline \multicolumn{3}{|c|}{ Weight status (ref.: Normal weight) } \\
\hline Obesity & $8.7(3.6,13.7)$ & $12.5(6.6,18.5)$ \\
\hline Overweight & $3.3(0.1,6.5)$ & $2.5(-0.9,5.9)$ \\
\hline Underweight & $6.1(1.6,10.6)$ & $1.5(-2.4,5.4)$ \\
\hline \multicolumn{3}{|c|}{ Panel B: Body image stress included } \\
\hline \multicolumn{3}{|c|}{ Weight status (ref.: Normal weight) } \\
\hline Obesity & $8.3(3.2,13.3)$ & $10.5(4.5,16.6)$ \\
\hline Overweight & $3.1(-0.1,6.3)$ & $1.6(-1.7,5.0)$ \\
\hline Underweight & $6.1(1.6,10.6)$ & $1.8(-2.1,5.7)$ \\
\hline Body image stress & $8.4(5.3,11.6)$ & $10.5(7.4,13.6)$ \\
\hline \multicolumn{3}{|c|}{ Panel C: Health status included } \\
\hline \multicolumn{3}{|c|}{ Weight status (ref.: Normal weight) } \\
\hline Obesity & $9.0(3.9,14.0)$ & $12.6(6.6,18.6)$ \\
\hline Overweight & $3.3(0.1,6.5)$ & $2.5(-0.8,5.9)$ \\
\hline Underweight & $3.3(0.1,6.5)$ & $2.5(-0.8,5.9)$ \\
\hline \multicolumn{3}{|c|}{ Health status (ref.: Excellent) } \\
\hline Good & $-1.3(-4.0,1.5)$ & $-3.0(-6.3,0.2)$ \\
\hline Fair & $-2.1(-5.2,1.1)$ & $-2.4(-5.7,1.0)$ \\
\hline Poor & $-1.7(-5.8,2.4)$ & $-2.9(-7.2,1.5)$ \\
\hline Very poor & $-15.7(-22.7,-8.6)$ & $2.8(-11.7,17.2)$ \\
\hline \multicolumn{3}{|c|}{ Panel D: Both body image stress and health status included } \\
\hline \multicolumn{3}{|c|}{ Weight status (ref.: Normal weight) } \\
\hline Obesity & $8.6(3.6,13.6)$ & $10.6(4.5,16.6)$ \\
\hline Overweight & $3.1(-0.1,6.3)$ & $1.7(-1.6,5.0)$ \\
\hline Underweight & $6.8(2.2,11.3)$ & $1.8(-2.1,5.8)$ \\
\hline Body image stress & $8.4(5.2,11.5)$ & $10.5(7.4,13.5)$ \\
\hline \multicolumn{3}{|c|}{ Health status (ref.: Excellent) } \\
\hline Good & $-1.1(-3.9,1.6)$ & $-2.8(-6.0,0.5)$ \\
\hline Fair & $-1.9(-5.0,1.2)$ & $-2.1(-5.4,1.1)$ \\
\hline Poor & $-1.6(-5.7,2.4)$ & $-2.5(-6.8,1.8)$ \\
\hline Very poor & $-15.3(-22.3,-8.2)$ & $3.7(-10.8,18.3)$ \\
\hline
\end{tabular}

Notes: Covariates include father's and mother's education, household economic status, number of cars at home, having no bedroom for the student, number of computers at home, residence area type, and survey year.

vocational high school as opposed to a general high school. We do not find strong evidence for the mediating role of body image stress and health status in the association between obesity and poorer school performance.

This study adds to a growing body of research concerning nonhealth consequences of excess weight. Although a negative relationship between obesity and academic performance has been established in western countries, few studies are available among Asian students. Given the rising tide of obesity sweeping South Korea and other Asian countries, these results are concerning. Without interventions that effectively reduce rising rates of obesity, Asia will soon experience the high health and financial costs of obesityrelated diseases currently affecting western countries. These results also provide a possible explanation on poorer labor market outcomes observed among obese adults by showing poorer school performance and a higher likelihood of attending vocational high school among adolescents with excess weight. The BMI tracking literature reveals that excess weight in adolescence greatly increases the risk of obesity in adulthood [27]. This study suggests that in South Korea, as in the west, labor market outcomes may also be greatly influenced by BMI at younger ages. Obese youth who have poorer grades and/or who enter a vocational track as opposed to a general high school will have a more difficult time entering university and/or competing for high-wage jobs in the future.

Two other findings merit attention. First, there is a higher magnitude of negative effects among females than males, and among middle school students compared with high school students. The highest magnitude of the negative effect 
is observed among female, middle school students. While obesity is negatively associated with self-reported school performance in middle school and general high school, the association is not significant in vocational school. It is not clear whether these differences are due to different peer effects by school type or selection process from middle to high school. Second, our results do not provide support that body image stress and health status explain a considerable portion of the variations in self-reported school performance or school choice by weight status. Future research is required to better understand the mechanism for the link between excess weight and poorer school performance in childhood and adolescence.

This analysis has many strengths, including the large, nationally representative sample size $(N=142783)$ and the ability to control for individual and family factors that are potentially correlated with both weight status and school performance in separate models by gender and school type. In doing so, we were able to identify interesting differences by gender and school type. Even after controlling for a rich set of potential confounders, our results suggest a considerable magnitude of association between obesity and poorer selfreported school performance for subsamples. This study, however, has several limitations. The primary limitation is the cross-sectional nature of the analyses. As a result, we cannot say with certainty that excess weight is causing poor school performance. Although we controlled for a number of factors thought to confound and mediate the relationship between weight and self-reported school performance, it is still possible that the direction of causation is reversed or that some unmeasured variable is causing both weight gain and poor performance [11, 12]. Given that two-way causality is plausible over multiple periods, a significant empirical challenge remains: to estimate the causal effect of obesity on academic performance in a dynamic modelling framework. Second, the analysis relies entirely on selfreported data, which may be limited in measuring overall school performance [28]. This can be especially problematic as two individuals with the same grades could self-report different school performance; likewise, self-report of weight and height may result in additional bias. However, the fact that our findings are consistent with those from other countries suggests that none of these issues are substantially biasing the results. Finally, the variable of body image stress in our study is only a crude measure of the negative psychological effects of excess weight. Future studies could use a well-developed and field-tested instrument to better capture the psychological consequences of obesity and test the mediating effects of obesity on school performance.

Despite these limitations, our study findings provide a useful basis for future research which may attempt to further explore these results using panel data and possibly identify the longer-term consequences of excess weight in adolescence in South Korea and other Asian countries.

\section{Conflict of Interests}

The authors declare no conflict of interests.

\section{Acknowledgments}

The data for this study were made available by the Korea Centers for Disease Control and Prevention (KCDC). This work was supported by an A*STAR infrastructure grant to the Duke-NUS Graduate Medical School Program in Health Services and Systems Research. The KCDC and A*STAR played no role in the conduct of the research or preparation of the manuscript. Mary Ann Bautista at the Duke-NUS provided editorial assistance.

\section{References}

[1] World Health Organization, "Fact sheet on obesity and overweight," World Health Organization Website, 2009, http://www.who.int/topics/obesity/en/.

[2] J. Cawley, "The impact of obesity on wages," Journal of Human Resources, vol. 39, no. 2, pp. 451-474, 2004.

[3] E. Han, E. C. Norton, and S. C. Stearns, "Weight and wages: fat versus lean paychecks," Health Economics, vol. 18, no. 5, pp. 535-548, 2009.

[4] S. Morris, "The impact of obesity on employment," Labour Economics, vol. 14, no. 3, pp. 413-433, 2007.

[5] F. Renna and N. Thakur, "Direct and indirect effects of obesity on U.S. labor market outcomes of older working age adults," Social Science and Medicine, vol. 71, no. 2, pp. 405-413, 2010.

[6] J. Greve, "Obesity and labor market outcomes in Denmark," Economics and Human Biology, vol. 6, no. 3, pp. 350-362, 2008.

[7] E. Han, E. C. Norton, and L. M. Powell, "Direct and indirect effects of teenage body weight on adult wages," Economics and Human Biology, 2011.

[8] A. G. Fowler-Brown, L. H. Ngo, R. S. Phillips, and C. C. Wee, "Adolescent obesity and future college degree attainment," Obesity, vol. 18, no. 6, pp. 1235-1241, 2010.

[9] N. H. Falkner, D. Neumark-Sztainer, M. Story, R. W. Jeffery, T. Beuhring, and M. D. Resnick, "Social, educational, and psychological correlates of weight status in adolescents," Obesity Research, vol. 9, no. 1, pp. 32-42, 2001.

[10] S. M. Shore, M. L. Sachs, J. R. Lidicker, S. N. Brett, A. R. Wright, and J. R. Libonati, "Decreased scholastic achievement in overweight middle school students," Obesity, vol. 16, no. 7, pp. 1535-1538, 2008.

[11] S. Alatupa, L. Pulkki-Råback, M. Hintsanen et al., "School performance as a predictor of adulthood obesity: a 21-year follow-up study," European Journal of Epidemiology, vol. 25, no. 4, pp. 267-274, 2010.

[12] S.-H. Cho, D. M. Lambert, H. J. Kim, and S. G. Kim, "Overweight Korean adolescents and academic achievement," Journal of Family and Economic Issues, vol. 30, no. 2, pp. 126$136,2009$.

[13] L. Mo-suwan, L. Lebel, A. Puetpaiboon, and C. Junjana, "School performance and weight status of children and young adolescents in a transitional society in Thailand," International Journal of Obesity, vol. 23, no. 3, pp. 272-277, 1999.

[14] A. Datar, R. Sturm, and J. L. Magnabosco, "Childhood overweight and academic performance: national study of kindergartners and first-graders," Obesity Research, vol. 12, no. 1, pp. 58-68, 2004.

[15] A. Datar and R. Sturm, "Childhood overweight and elementary school outcomes," International Journal of Obesity, vol. 30, no. 9, pp. 1449-1460, 2006. 
[16] S. Judge and L. Jahns, "Association of overweight with academic performance and social and behavioral problems: an update from the early childhood longitudinal study," Journal of School Health, vol. 77, no. 10, pp. 672-678, 2007.

[17] R. Crosnoe and C. Muller, "Body mass index, academic achievement, and school context: examining the educational experiences of adolescents at risk of obesity," Journal of Health and Social Behavior, vol. 45, no. 4, pp. 393-407, 2004.

[18] R. A. Krukowski, D. Smith West, A. Philyaw Perez, Z. Bursac, M. M. Phillips, and J. M. Raczynski, "Overweight children, weight-based teasing and academic performance," International Journal of Pediatric Obesity, vol. 4, no. 4, pp. 274 280, 2009.

[19] J.-S. Kim and K. Lee, "The relationship of weight-related attitudes with suicidal behaviors in Korean adolescents," Obesity, vol. 18, no. 11, pp. 2145-2151, 2010.

[20] Korea Centers for Disease Control and Prevention, User guide for the 2005-2007 Korean Youth Health Risk Behavior Online Survey, Seoul, Korea, 2009.

[21] Korea Research Institute for Vocational Education and Training (KRIVET), "Human Resources Development Indicators in Korea 2009," Research Data 2009-14, Seoul, Korea, 2009.

[22] Korea Centers for Disease Control and Prevention. The Korean Pediatric Society, "The Committee for the Development of Growth Standard for Korean Children and Adolescents, "Korean children and adolescents growth standard (commentary for the development of 2007 growth chart)," Government report, Division of Chronic Disease Surveillance, Seoul, Korea, 2007.

[23] Y.-H. Khang and M. J. Park, "Trends in obesity among Korean children using four different criteria," International Journal of Pediatric Obesity, vol. 6, no. 3-4, pp. 206-214, 2011.

[24] S. A. Haas, L. R. Jehn, and P. D. Meek, "Regional variation in stroke mortality in Wisconsin, 1989-1998," Wisconsin Medical Journal, vol. 101, no. 3, pp. 28-31, 2002.

[25] J. J. Reilly, E. Methven, Z. C. McDowell et al., "Health consequences of obesity," Archives of Disease in Childhood, vol. 88, no. 9, pp. 748-752, 2003.

[26] S. A. Haas and N. E. Fosse, "Health and the educational attainment of adolescents: evidence from the NLSY97," Journal of Health and Social Behavior, vol. 49, no. 2, pp. 178-192, 2008.

[27] J. M. Nonnemaker, A. A. Morgan-Lopez, J. M. Pais, and E. A. Finkelstein, "Youth BMI trajectories: evidence from the NLSY97," Obesity, vol. 17, no. 6, pp. 1274-1280, 2009.

[28] T. Huang, M. I. Goran, and D. Spruijt-Metz, "Associations of adiposity with measured and self-reported academic performance in early adolescence," Obesity, vol. 14, no. 10, pp. 1839$1845,2006$. 


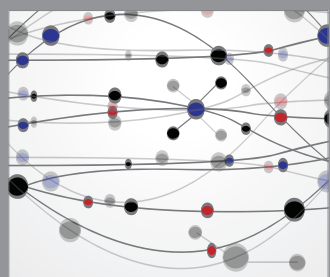

The Scientific World Journal
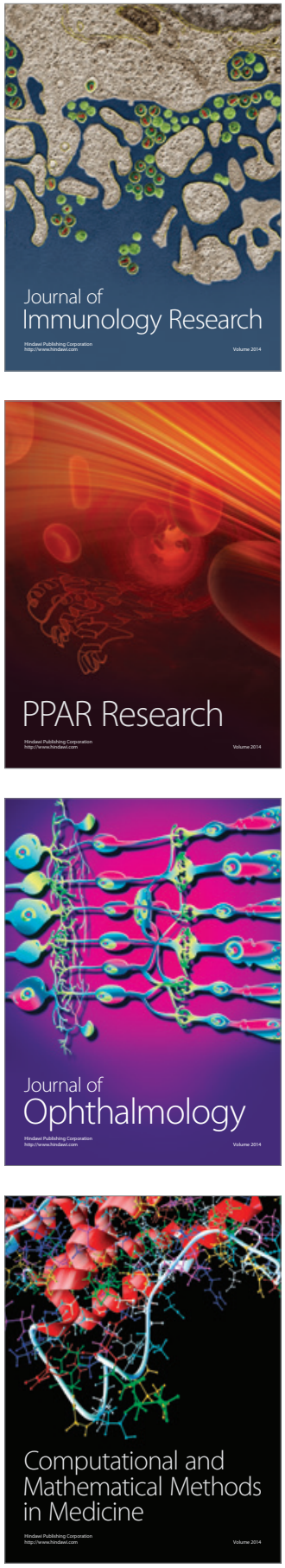

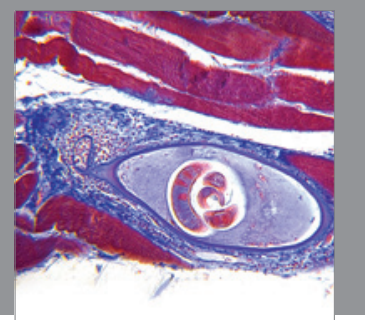

Gastroenterology

Research and Practice
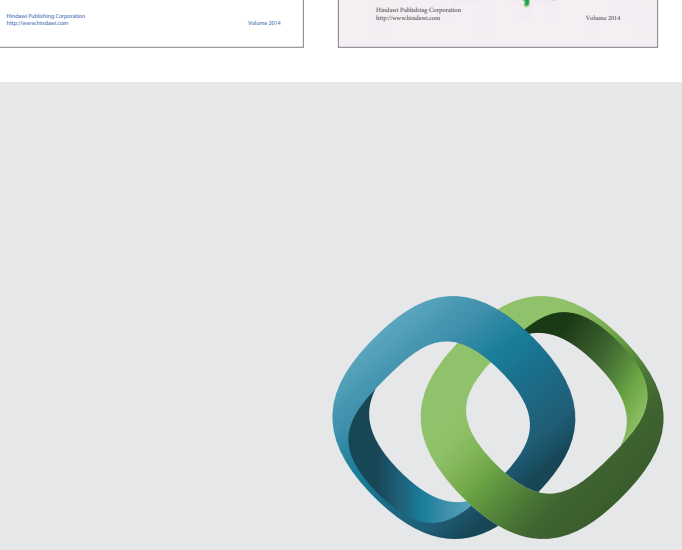

\section{Hindawi}

Submit your manuscripts at

http://www.hindawi.com
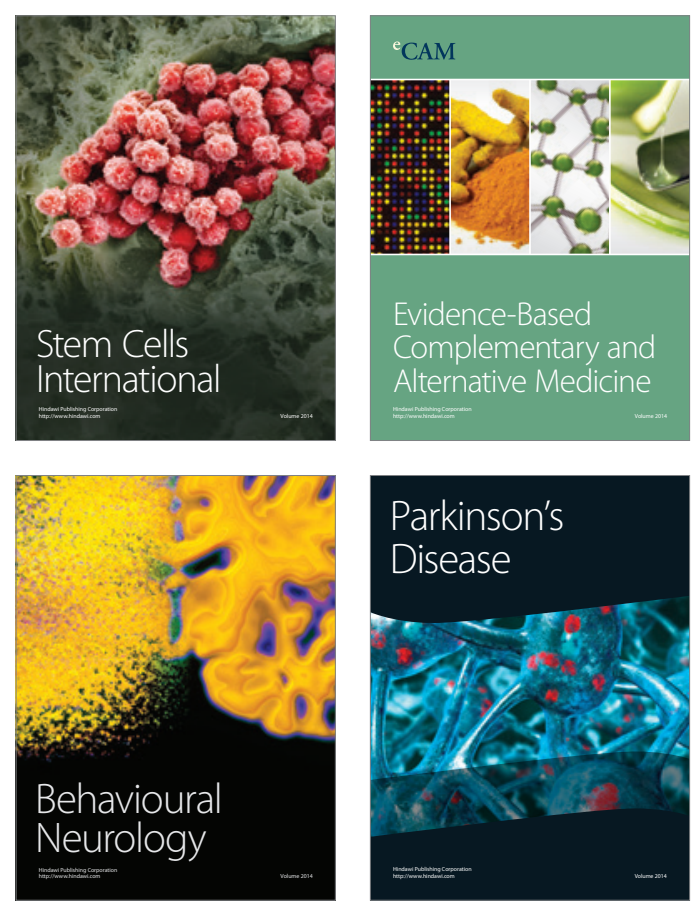

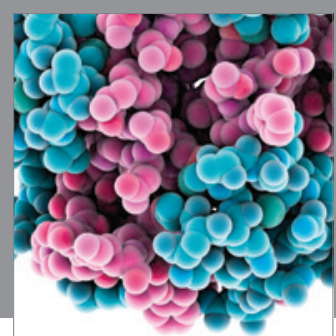

Journal of
Diabetes Research

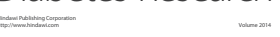

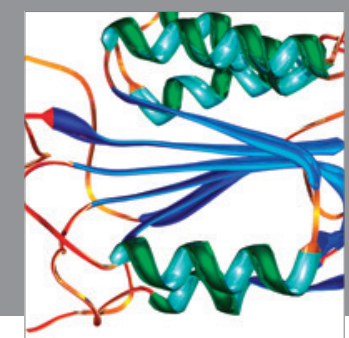

Disease Markers
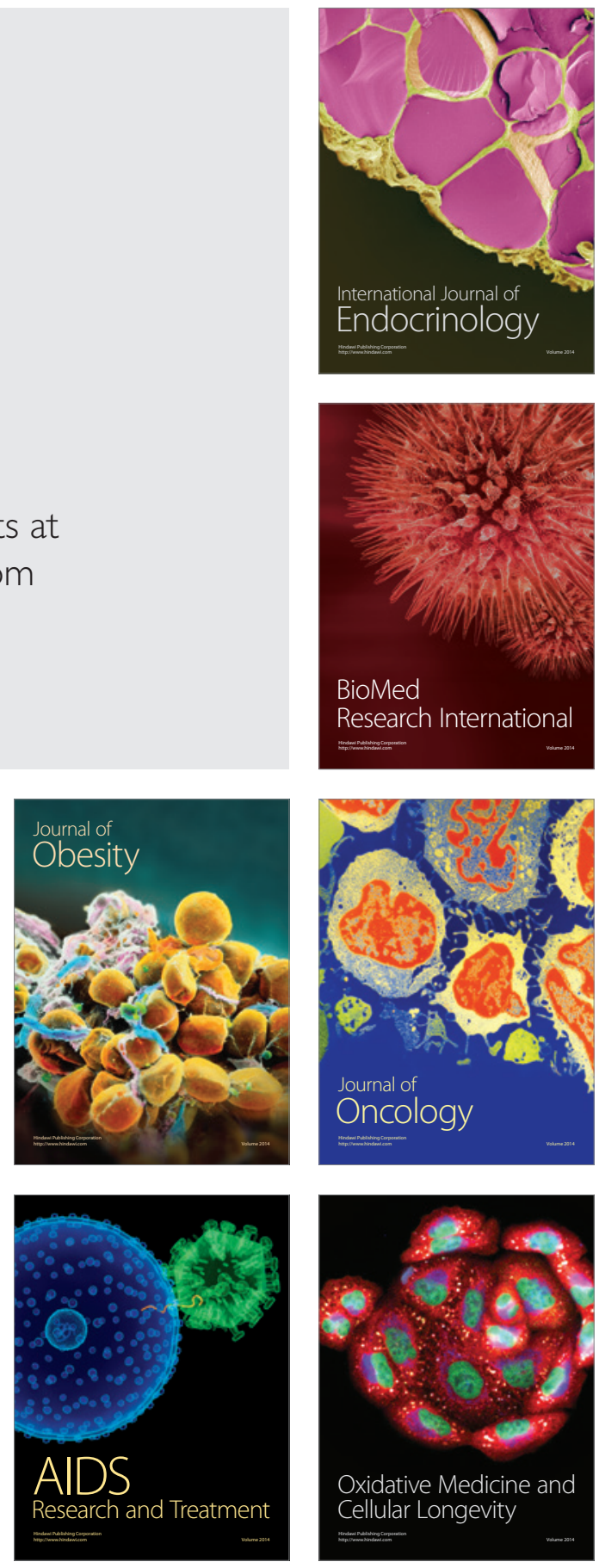